\title{
Atomoxetine Might Be More Effective in Improving Sluggish Cognitive Tempo Symptoms Compared to Methylphenidate: A Case Report
}

\author{
Akın Tahıllığlu ${ }^{1}$ and Eyüp Ercan ${ }^{1}$ \\ ${ }^{1}$ Ege University Medical Faculty Hospital
}

August 3, 2020

\begin{abstract}
We report the differential diagnostic procedure and pharmacological treatment process of a case with Sluggish Cognitive Tempo (SCT) and subthreshold ADHD. The case had much more benefit from atomoxetine in terms of SCT symptoms compared to methylphenidate.

\section{Title: ATOMOXETINE MIGHT BE MORE EFFECTIVE IN IMPROVING SLUGGISH COGNITIVE TEMPO SYMPTOMS COMPARED TO METHYLPHENIDATE: A CASE RE- PORT}

Akın TAHILLIOĞLU1 ${ }^{1}$, Eyüp Sabri ERCAN ${ }^{1}$

Ege University Faculty of Medicine, Department of Child and Adolescent Psychiatry - Turkey

Corresponding Author:

Akın TAHILLIOĞLU e-mail:tahillioglua@gmail.comPhone number: $\quad+905538993050$ ORCID ID:https://orcid.org/0000-0002-3952-3672

Acknowledgements: We all thank to the pedagogue and the psychologists of Ege University Child and Adolescent Psychiatry department for observing the patient in the playroom and performing his psychometric tests. Since the patient has been followed for a long time such as four and a half years, his several clinical examinations were performed by some of other colleagues in the department. We also would like to thank to those colleagues.

Abstract: We report the differential diagnostic procedure and pharmacological treatment process of a case with Sluggish Cognitive Tempo (SCT) and subthreshold ADHD. The case had much more benefit from atomoxetine in terms of SCT symptoms compared to methylphenidate.

Keywords: sluggish cognitive tempo; attention-deficit/ hyperactivity disorder; methylphenidate; atomoxetine; treatment

Key Clinical Message: Although there is no proven evidence regarding pharmacotherapy of Sluggish Cognitive Tempo (SCT), we experienced that atomoxetine had much more effects in decreasing SCT symptoms compared to methylphenidate in a case with SCT and subthreshold ADHD.

\section{INTRODUCTION}

Sluggish Cognitive Tempo (SCT) is a disorder characterized by a range of symptoms such as mental slowness, daydreams, lack of energy, staring with empty eyes (1). Although SCT and Attention-Deficit/ Hyperactivity 
Disorder (ADHD) are often presented together, increasing current evidence supports that SCT is a separate and independent diagnostic entity differentiating from ADHD. Many researches highlight the overlap between SCT and ADHD. 39\% of individuals with ADHD were found to have SCT; whereas $59 \%$ of individuals with SCT had ADHD as well (2). In another study, it was stated that the proportion of patients with pure SCT but not diagnosed with ADHD was $40 \%$ (3).

The literature on possible treatment modalities of SCT is very scarce. It was detected that methylphenidate improves attention problems, although it does not improve core SCT symptoms in limited studies (4). There are also literature findings indicating that methylphenidate therapy has not association with improving SCT symptom load $(5,6)$. A current study also points out that Sluggish/sleepy symptoms of SCT do not respond to methylphenidate, whereas SCT/Daydreamy symptoms have no association with methylphenidate nonresponse (7). The results of a study, in which atomoxetine was used, showed that SCT symptom scores decreased as a result of 16 weeks of treatment of atomoxetine, and academic improvement was observed (5). This study is important because it was the first study to demonstrate improvements in SCT with medication. On the other hand, another double-blind placebo-controlled study suggested that atomoxetine provides control over ADHD symptoms but has minimal effect on SCT symptoms (8).

When existing data are scrutinized, the lack of studies on SCT treatment is noticeable. In addition, there are no case reports on the differential diagnostic process and psychopharmacologic treatment process in individuals with SCT. Exploring how the standard ADHD treatment protocol affects SCT symptoms in a case with subthreshold ADHD, and intense SCT symptoms, is very crucial for clinicians in terms of shaping their treatment approaches about this kind of patients. For these reasons, we aimed to investigate the differential diagnostic procedure of a case with SCT and subthreshold ADHD symptoms and to determine if there are improvements in SCT symptoms and to what extent there has been improvement along with pharmacological treatment process.

\section{CASE HISTORY}

The 5-year-and 6-month-old boy was first referred to our outpatient clinic with complaints of being too stagnant compared to their peers, not looking at someone when his name was called, slow-moving, absentmindedness, fear of darkness, and not being able to go to the toilet alone. It was learned that there had been a neurological application for him before and that there were no findings in favor of epilepsy in the electroencephalography (EEG) examination. In order to investigate autism spectrum disorder (ASD), he was observed by a pedagogue in a playroom observation. However, no additional clinical findings related to ASD were observed. After his adaptation to the primary school, he learned to read and write without any delay, and his academic achievement was at the level of the class average. When he was seven years old, he filled the Children Depression Inventory (CDI) $(9,10)$ in order to be examined for the presence of depression. He got 4 points from this scale (the cut-off point is 19). Clinical psychiatric examination of the case revealed that there were not enough signs of attention deficit that would affect his daily functionality, and also there were no signs of hyperactivity and impulsivity. The observation reports of his teacher stated that he used to move very slowly, look at something at a long time with empty eyes, daydream, but academically did not have problems in his lessons. During this period, the case was followed by a treatment strategy plan including behavioral interventions without medication.

When he was 7-years and 4-months old, he received 30 points from the Barkley Child Attention Survey (Barkley SCT Screening Scale - BCAS) filled by the parents. The BCAS score filled by the teacher was 27. He got 6 points from parent-rated 4 SCT-scanning items (SCT-CBCL) of Child Behavior Check List (CBCL) $(12,13)$, and 5 points from teacher-rated 4 SCT-scanning items (SCT-TRF) of Teacher's Report Form (TRF) $(13,14)$. A semi-structured interview to identify comorbidities that may accompany his psychopathology, Schedule for Affective Disorders and Schizophrenia for School-Age Children -Present and Lifetime Version (K-SADS-PL) $(15,16)$ was applied to the case and the parents. According to the K-SADS-PL, subthreshold inattentive symptoms not meeting ADHD diagnostic criteria were detected. Inattention scores of parent and teacher-rated DSM-IV Based Screening and Evaluation Scale for Disruptive Behavioral Disorders (ADHD Rating Scale - IV, ADHD-RS-IV) $(17,18)$ were 14 and 7 points, whereas hyperactivity/impulsivity scores 
were 1 and 0, respectively. The Weschler Intelligence Scale for Children - Revised Version (WISC-R) (19, 20) was applied to evaluate the intelligence capacity of the case. According to the test, it was established that he had normal intelligence capacity with a verbal Intelligence Quotient (IQ) score of 88, a performance IQ score of 128, and a total IQ score of 108. In order to treat his subthreshold ADHD symptoms, Immediate Release Methylphenidate was started at a dose of $10 \mathrm{mg} /$ day. After two months, it was determined that the case benefited from the drug in terms of moderate attention problems, but the SCT symptoms did not diminish. The dose of methylphenidate was increased to $15 \mathrm{mg}$ /day. Within the next 6 months, SCT symptoms, such as daydreaming, staring with empty eyes and slow-moving remained at similar severity. Within this particular process, the dose of methylphenidate was increased up to $30 \mathrm{mg} /$ day. During this period, parentrated and teacher-rated BCAS scores were 26 and 25 points, respectively. He got 4 points from parent-rated SCT-CBCL scale and 6 points from teacher-rated SCT-TRF scale. After 27 months of methylphenidate use, although the moderate inattentive symptoms almost completely declined, clinical psychiatric examinations determined that this treatment could not be sufficiently effective on SCT symptoms. Indeed, reports from the teacher and parents confirmed this condition. The pharmacotherapy table and the graphs regarding the scores obtained from the scales are shown in Figure -1 .

(Insert Figure - 1 about here)

Figure - 1: Graphs of the patient's pharmacological treatment history and scores from scales

Figure legend: ADHD-RS-IV: DSM-IV Based Screening and Evaluation Scale for Disruptive Behavior Disorders (IN: Inattention subscale (scoring between 0 and 27 points), HI: Hyperactivity/impulsivity subscale (scoring between 0 and 27 points), BCAS: Barkley Child Attention Survey (scoring between 12 and 48 points), SCT-CBCL: SCT-related 4 items of the Child Behavior Check List (scoring between 0 and 8 points), SCT-TRF: SCT-related 4 items of Teacher's Report Form (scoring between 0 and 8 points).

When the patient was 9-years and 7-months old, methylphenidate treatment was discontinued and switched to atomoxetine. The starting dose of atomoxetine was $10 \mathrm{mg} /$ day and the drug dosage was increased up to $43 \mathrm{mg}$ /day within 3 months. The dosage of atomoxetine was fixed at a dose of $43 \mathrm{mg} /$ day and followed for two months at this dose. The family and the patient reported that he had a headache and dizziness as side effects. For this reason, the dose of atomoxetine was slightly reduced to $36 \mathrm{mg} /$ day. After two months of using the drug at this dose, headaches disappeared, and dizziness complaints decreased significantly. He used atomoxetine for 7 months in total. Clinical examinations and the observation notes obtained from the teacher and his family indicated that there was a more significant improvement in SCT symptoms compared to the period when methylphenidate was used. It was determined that moderate inattention problems almost disappeared, and there were noticeable improvements in SCT symptoms such as absent-mindedness, long reaction time when his name was called, and staring with blank eyes. The BCAS scores filled by the family and the teacher decreased to 20 points and 16 points, respectively. Eventually, parent-rated SCTCBCL scale score was 0 , and teacher-rated SCT-TRF scale score was 1 point (Figure - 1). K-SADS-PL was re-administered approximately 3 years after the first practice. No additional diagnostic comorbidity was detected, except subthreshold inattentive symptoms. The case and his parents were informed of the case study and written inform consents were obtained from them. This case study was approved by Ethical Committee of Medical Researches of Ege University (decision no: 20-2T/7).

\section{DISCUSSION}

\section{Differential Diagnostic Process in the Case with SCT}

Many literature data point out that SCT is in less association with externalizing disorders (i.e. disruptive behavioral disorders), whereas more associated with internalizing disorders (i.e. anxiety, depression) as opposed to ADHD $(2,21-23)$. In our case, no evidence was found to suggest the presence of oppositional defiant disorder or conduct disorder. But, especially at the beginning of clinical follow-up, the presence of anxiety symptoms such as not being able to go to the toilet alone and the fear of darkness is a condition that is consistent with the literature and is expected. However, there were no additional signs of anxiety disorder to diagnose the patient. Depression can accompany SCT as an internalizing symptom dimension, 
too. However, there was not enough evidence to clinically diagnose the case with major depression. The case was moving slowly and had low energy. These findings may perhaps be confounded with the "anergia" symptom of depression. Even if it was accepted as anergia, the presence of "anergia" alone would not adequately explain the depression of the case.

It was also noted that the patient did not immediately look when his name was called, especially around 6 years of age. Hence, a possible ASD diagnosis was investigated in the case. However, the lack of any findings of the case in language, social communication and empathy fields that support ASD diagnosis has kept us away from considering ASD. The relationship between ASD and SCT was first examined in a current study and SCT symptoms were found to be significantly higher in adolescent cases with ASD (24). An up-to-date study in young adults with ASD found that one-third of these cases had high levels of SCT symptoms (25). The coexistence of these two psychopathologies may be associated with a possible similarity or overlap between their symptoms. Since the "processing speed slowness" observed in SCT can also be observed frequently in individuals with intellectual disability, it is important to distinguish these two different psychopathological structures. For this purpose, we wanted to measure the intelligence capacity of the case, applying WISC-R, and finding that the patient had a normal estimated IQ score and had no mental insufficiency.

The case has inattention symptoms that do not affect his daily functionality. Moreover, according to both psychiatric examinations conducted on DSM-5 diagnostic criteria and K-SADS-PL clinical interviews, the patient had subthreshold symptoms of inattentive presentation of ADHD. One study found that 44-54\% of patients with SCT had ADHD diagnosis, 27-35\% of patients with ADHD had SCT characteristics, and $28-46 \%$ of children with SCT present an independent phenotype not having ADHD or depression diagnoses (26).

\section{Treatment Process in the Case with SCT}

The case was followed without medication for about two years after the first application. In the following process, the drug treatment began, and he has been receiving drug treatment for approximately three years. He had subthreshold ADHD symptoms as well as SCT symptoms. Although the patient did not fulfill the diagnostic criteria of ADHD accurately, we did not want to allow his subthreshold ADHD symptoms to remain untreated. An open-label clinical trial suggests that subthreshold ADHD symptoms responded positively to six weeks of atomoxetine treatment in adults demonstrating atypical manifestations or insufficient symptoms of ADHD (ADHD-Not Otherwise Specified) (27). Between the onset and discontinuation of methylphenidate treatment, which lasted about 27 months, there was only a small reduction in total SCT scores reported by the parents and the teacher. It was observed that he continued to exhibit significant SCT symptomatology and scored above threshold values. On the flip side, there have been higher rates of improvements in the signs of moderate attention deficit symptoms of the case. An up-to-date study suggested there were improvements in the scores of SCT-Total and SCT-Daydreams both at home and at school after the use of methylphenidate, and SCT-Sluggish scores were found to have improvements only at school. The study also claimed that the presence of SCT symptoms in children with ADHD had negative effects on methylphenidate treatment in the school area (28). Another study points out that SCT-sluggish/sleepy appearance symptoms do not respond to methylphenidate, whereas SCT-daydreaming symptoms are not associated with methylphenidate nonresponse (7). Similar to this study, our case had no significant improvement in the signs of slow movement, absent-mindedness, and sleepy appearance, especially when medicated with methylphenidate. However, contrary to what was noted in these two studies, there was no significant improvement in daydreaming symptoms despite methylphenidate treatment.

Since it was determined that the case did not benefit enough from methylphenidate in terms of SCT, the medication was switched to atomoxetine. Using atomoxetine for 7 months, he was found to have higher acceleration and higher rates of decline in SCT scores based on parents and teachers. Wietecha's study is the first study in the literature showing improvement in SCT with medication. In this double-blind placebocontrolled study, three groups diagnosed with "ADHD+Dyslexia", "ADHD only" and "Dyslexia only" were initiated atomoxetine and 16 weeks of treatment were administered. Significant reductions in both ADHD 
and SCT symptoms were detected in all three groups. A positive correlation was determined between ADHD and SCT symptoms in terms of improvements in these symptoms with atomoxetine treatment (5). In line with this study, SCT symptoms of our case have shown improvement with atomoxetine.

Our case report has some strengths and limitations. This is the first study in the literature investigating the differential diagnosis and treatment process of a patient with SCT. So far, it has been observed that either methylphenidate or atomoxetine is used for SCT treatment in clinical trials, but there is no publication in the literature where both drugs are involved and compared. From this point of view, our case report provides the first data in this field by simultaneously observing and comparing the effects of methylphenidate and atomoxetine together on SCT symptoms on a case-by-case basis. In addition, the absence of other comorbidities including threshold ADHD made the results of this case in the course of treatment clearer and more valuable. The study might help clinicians to better analyze and develop more appropriate treatment strategies regarding SCT. Furthermore, in order to confirm SCT diagnosis, both the parents and the teacher were asked to fill the scales related to SCT periodically, and these scales have been supportive of the clinician's psychiatric examination. In this way, information related to SCT symptoms of the case could be obtained from multiple informants. These scales also monitored the pharmacotherapy process, making it easier to find out the results of treatment effectiveness.

As for the limitations; the results cannot be generalized for all cases with SCT since the findings are valid for one case alone. The findings should be replicated and clinical trials with a higher number of cases are needed.

In conclusion, both methylphenidate and atomoxetine, which are commonly used for ADHD, were used for sufficient time in a case, who did not have any other comorbidity as well as subthreshold ADHD symptoms and whose SCT symptoms were severely observed. Both drugs have improved the signs of moderate attention deficits. Although there were no high response rates to SCT in both drugs, SCT symptoms have decreased much more and faster in the use of atomoxetine compared to methylphenidate. These results should be replicated, and randomized controlled trials are needed with more patients.

Conflict of Interest: ESE is on the advisory board for Sanofi Turkey. AT declares that there is no conflict of interest.

Data Availability Statement: We have not shared the data from this study yet.

Author Contributions: A.T. contributed to the processes of investigation, validation, formal analysis, original draft preparation, review and editing. E.S.E. contributed to the processes of conceptualization, methodology, investigation, validation, review \& editing and supervision.

\section{REFERENCES}

1. Barkley, R. A. (2015). Concentration deficit disorder (sluggish cognitive tempo). In Attention-deficit hyperactivity disorder: A handbook for diagnosis and treatment (pp. 81-115). New York, NY: Guilford Press.

2. Barkley R.A. (2012) Distinguishing sluggish cognitive tempo from attention-deficit/hyperactivity disorder in adults. J. Abnorm. Psychol. 121(4):978-990.

3. Barkley, R. A. (2013). Distinguishing sluggish cognitive tempo from ADHD in children and adolescents: Executive function- ing, impairment, and comorbidity. Journal of Clinical Child \& Adolescent Psychology, 42(2), 161-173.

4. Barkley RA, DuPaul GJ, McMurray MB. (1991) Attention deficit disorder with and without hyperactivity: clinical response to three dose levels of methylphenidate. Pediatrics. 1991;87(4):519-31.

5. Wietecha L, Williams D, Shaywitz S, Shaywitz B, Hooper SR, Wigal SB, Dunn D, McBurnett K. (2013) Atomoxetine improved attention in children and adolescents with attention-deficit/hyperactivity disorder and dyslexia in a 16 week, acute, randomized, double-blind trial. J Child Adolesc Psychopharmacol. 23(9):605-13. 
6. Ludwig, H. T., Matte, B., Katz, B., \& Rohde, L. A. (2009). Do sluggish cognitive tempo symptoms predict response to methylphenidate in patients with attention-deficit/hyper- activity disorder-inattentive type? Journal of Child and Adolescent Psychopharmacology, 19(4), 461-465.

7. Froehlich, T. E., Becker, S. P., Nick, T. G., Brinkman, W. B., Stein, M. A., Peugh, J., \& Epstein, J. N. (2018). Sluggish cognitive tempo as a possible predictor of methylphenidate response in children with ADHD: A randomized controlled trial. The Journal of Clinical Psychiatry, 79(2),17m11553.

8. McBurnett, K., Clemow, D., Williams, D., Villodas, M., Wietecha, L., \& Barkley, R. (2017). Atomoxetine-related change in slug- gish cognitive tempo is partially independent of change in attention-deficit/hyperactivity disorder inattentive symptoms. Journal of Child and Adolescent Psychopharmacology, 27, 38-42.

9. Kovacs, M. (1980/1981). Rating scale to depression in school-aged children. Acta Paedopsychiatr, 46: $305-15$.

10. Öy, B. (1990). Çocuklar için depresyon ölçeğinin öğrenciler ve çocuk ruh sağlığı kliniğine başvuran çocuklarda uygulanması. Çocuk Psikiyatrisi Uzmanlık Tezi. Ankara.

11. Frrat, S., Bolat, G. U., Gul, H., Baytunca, M. B., Kardas, B., Aysev, A., \& Ercan, E. S. (2018). Barkley child attention scale validity reliability study. Dusunen Adam: The Journal of Psychiatry and Neurological Sciences, 31, 284-293.

12. Achenbach, T. (1991). Manual for the Child Behavior Checklist/4-18 and 1991 profile. Burlington, VT: University of Vermont.

13. Erol N, Arslan BL, Akçakın M (1995) The adaption and standardization of the Child Behavior Checklist among 6-18 year old Turkish children. Eunethydis: European Approaches to Hyperkinetic Disorder, J Sergeant (Ed). Zurich: Fotoratar, s. 97-113.

14. Achenbach TM. Manual for the teacher's report form and 1991 profle. Burlington: University of Vermont Department of Psychiatry; 1991.

15. Kaufman, J., Birmaher, B., Brent, D., Rao, U., Flynn, C., Moreci, P., Williamson, D. \& Ryan, N. (1997). Schedule for affective disorders and schizophrenia for schoolage children-present and lifetime version (K-SADS-PL): Initial reliability and validity data. Journal of American of Academy Child and Adolescent Psychiatry, 36 (7): 980-988.

16. Gökler, B., Ünal, F., Pehlivantürk, B., Kültür, EÇ., Akdemir, D., Taner, Y. (2004). Okul çağı çocukları için duygulanım bozuklukları ve şizofreni görüşme çizelgesi-şimdi ve yaşam boyu şekli- Türkçe uyarlamasının geçerlik ve güvenirliği. Çocuk ve Ergen Ruh Sağlığı Dergisi, 11 (3): 109-116.

17. Turgay A. (1994) Disruptive Behavior Disorders Child and Adolescent Screening and Rating Scales for Children, Adolescents, Parents and Teachers. West Bloomfield (Michigan), Integrative Therapy Institute Publication,

18. Ercan ES. (2001). Development of A Test Battery or the Assessment of Attention Deficit Hyperactivity Disorder Turk J. Child Adolesc Ment Health. 2001; 8(3): 132-144.

19. Wechsler D. (1974). WISC-R Manual fort he Wechsler Intelligence Scale for Children revised. New York: Psychological Corporation.

20. Savaşır I, Şahin N. (1995). Wechsler Çocuklar için Zeka Ölçeği (WISC-R) El Kitabı. Ankara. Türk Psikologlar Derneği Yayınları.

21. Becker, S. P., Leopold, D. R., Burns, G. L., Jarrett, M. A., Langberg, J. M., Marshall, S. A. et al. (2016). The internal, external, and diagnostic validity of sluggish cognitive tempo: A meta-analysis and critical review. Journal of the American Academy of Child \& Adolescent Psychiatry, 55, 163-172.

22. Fenollar Cortés, J., Servera, M., Becker, S. P., \& Burns, G. L. (2017). External validity of ADHD inattention and sluggish cognitive tempo dimensions in Spanish children with ADHD. Journal of Attention Disorders, 21, 655-666. doi:10.1177/ 1087054714548033

23. Flannery, A. J., Becker, S. P., \& Luebbe, A. M. (2014). Does emotion dysregulation mediate the association between sluggish cognitive tempo and college students' social impairment? Journal of Attention Disorders. Advance online publication. doi:10.1177/ 1087054714527794

24. Duncan A, Tamm L, Birnschein AM, Becker SP (2019) Clinical correlates of sluggish cognitive tempo in adolescents with autism spectrum disorder. Autism. 2019 Aug;23(6):1354-1362. doi: 
$10.1177 / 1362361318811329$.

25. Brewe AM, Simmons GL, Capriola-Hall NN, White SW. (2020) Sluggish cognitive tempo: An examination of clinical correlates for adults with autism. Autism. 2020 Feb 7:1362361319900422. doi: $10.1177 / 1362361319900422$.

26. Servera, M., Sáez, B., Burns, G. L., \& Becker, S. P. (2018). Clinical differentiation of sluggish cognitive tempo and attention-deficit/hyperactivity disorder in children. Journal of Abnormal Psychology, 127, 818-829. doi:10.1037/ abn0000375

27. Surman C, Hammerness P, Petty C, Doyle R, Chu N, Gebhard N, Williams C, Biederman J. (2010) Atomoxetine in the treatment of adults with subthreshold and/or late onset attention-deficit hyperactivity disorder-not otherwise specified (ADHD-NOS): a prospective open-label 6-week study. CNS Neurosci Ther. 2010 Spring;16(1):6-12. doi: 10.1111/j.1755-5949.2009.00124.x.

28. Firat S, Gul H, Aysev A. (2020) An Open-Label Trial of Methylphenidate Treating Sluggish Cognitive Tempo, Inattention, and Hyperactivity/ Impulsivity Symptoms Among 6- to 12-Year-Old ADHD Children: What Are the Predictors of Treatment Response at Home and School? J Atten Disord. 2020 Feb 17:1087054720902846. doi: 10.1177/1087054720902846. 
Change in the scale scores associated with ADHD in pharmacological treatment process

14

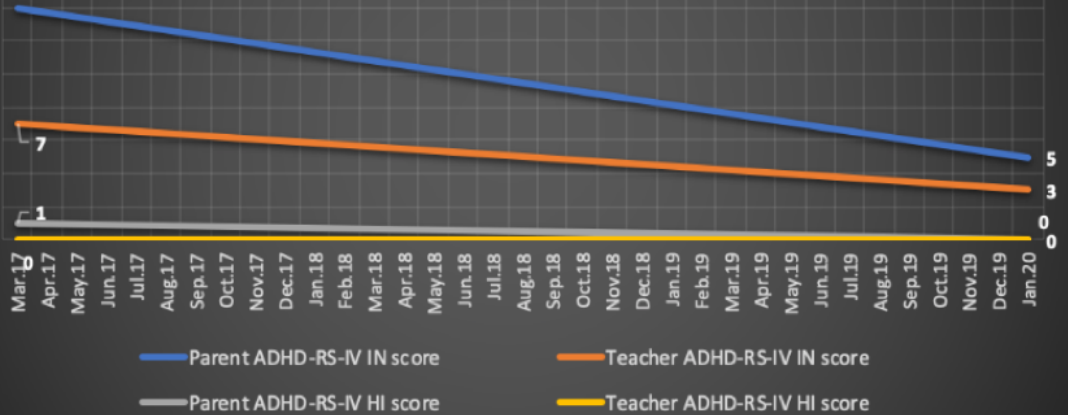

Change in the scale scores associated with SCT in pharmacological treatment process

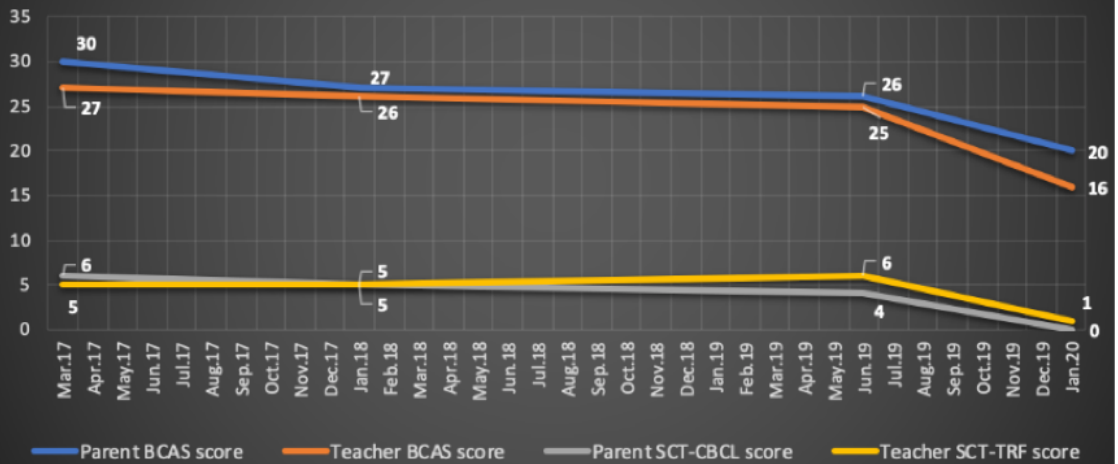

The history of pharmacological treatment process of the case

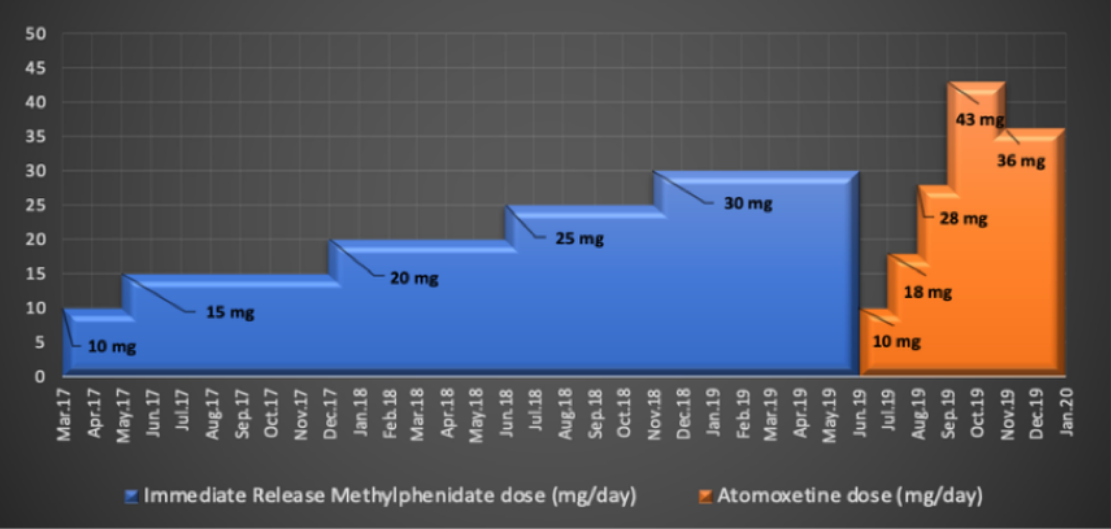

